\title{
A COMPARATIVE STUDY ON USER SATISFACTION WITH AN OBSERVATORY BETWEEN SARAKURA AND TAKATO MOUNTAIN, JAPAN
}

\author{
DAIWEI LIU \& BART JULIEN DEWANCKER \\ Department of Architecture, University of Kitakyushu, Japan
}

\begin{abstract}
The hilltop observatory is a basic sightseeing facility, which is often built with tourist attractions and natural scenery. So, although an observatory is a type of architectural space with both indoor and outdoor designing, they have received little attention and research. Whether the facilities will be effectively utilized is not only related to the management, operation and maintenance of scenic spots, but also determines the tourist experience. In Kitakyushu, Fukuoka, Japan has its two main mountains: the Sarakura Mountain and the Takato Mountain. The peak observatories on the hills are open facilities for free use by the public. In addition, the traditional tourist, leisure, exercise, assembly, photography, outdoor learning and other types of civic activities are also here. Whether the original construction of the facilities for tourists could meet our new demands or not is questionable. In this study, two objects and the evaluation of the users toward their using experiences were compared, and the space demand of the users and the degree of satisfaction were explored. It puts forward suggestions to optimize the observatory facilities, and provide a reference for the future design of this type of observatory.
\end{abstract}

Keywords: public park, satisfaction, observatory, gazebo, Kitakyushu.

\section{INTRODUCTION}

The use of public facilities and public satisfaction often change over time. The hilltop view terrace is used as a tourist facility to help visitors better look up and enjoy the scenery. However, with increasing demand for quality of life, the observatory in top of mountains is also used by more and more citizens, and its functions are becoming more diverse. Well, the original design for a single function of the terrace can be now diversified demand to meet, triggered our thinking and interest. We selected two peak terraces from Japan to investigate the satisfaction of visitors.

There are two mountains in Kitakyushu City, Fukuoka. The Sarakura and Takato. On the peak area of the hills, Ferris platform and supporting facilities for tourist leisure tour was built decades ago. Because the great viewing from the observatory, the scenery of the city attracting tourists to the city from long time ago. As a public facility of the city, two peaks were built the road to the parking near the top of the mountain, visitors can also walk along the mountain road. Takato Mountain is located 6.5 kilometers north than Sarakura Mountain. At $124 \mathrm{~m}$ above sea level, tourists and vehicles basically use the same road up the mountain, and the viewing terrace is mainly facing the east. Sarakura Mountain is as high as 622 meters, mainly for the viewing terrace on the north side, and Takato peak at. Because of the high altitude, overlooking the whole Kitakyushu City, it is designated as the main sightseeing spot of Kitakyushu City, and the mountain climbing cable car has been built. Cable car opens almost every day in the year and take around ten minutes to the top.

\section{PURPOSE AND METHOD}

\subsection{Purpose of this study}

The purpose of this study is to find out how satisfied people are when using observatory and the main factors that affect them. Though the existing facilities in peak area is similar, 
people of different ages and goals, may have varying degrees of satisfaction with their use of the experience. Their use of observatory and personal preferences also affect their assessment of their visiting experiences. We hope to find out whether there is any connection between them. What issues are more likely to be taken into account in different groups of people, thereby providing advice on the design, planning and operations management of the outlook, as well as providing a reference for this type of space design in the future.
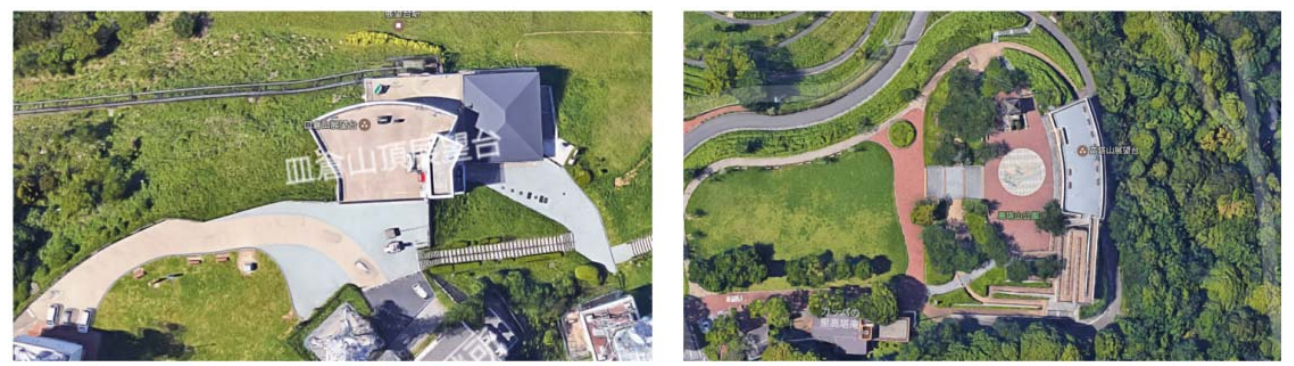

Figure 1: Sarakura Mountain (left) and Takato Mountain (right).

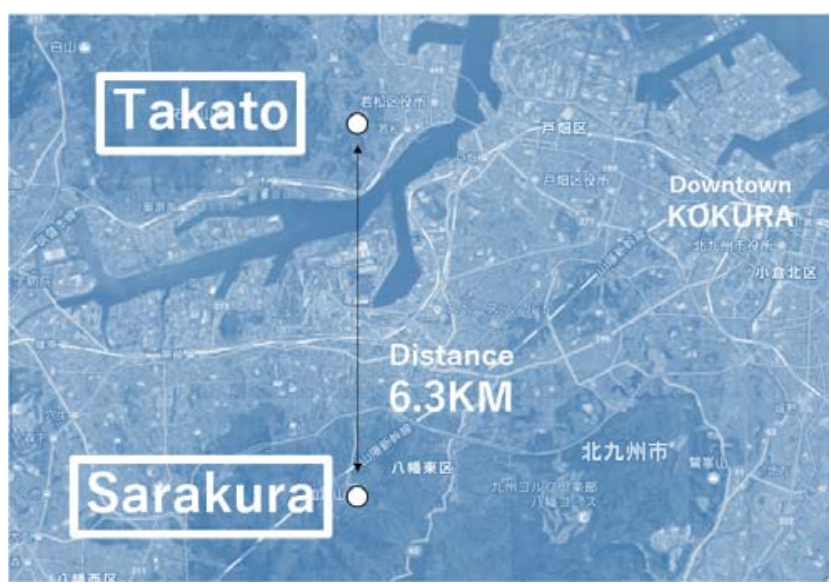

Figure 2: Location of the mountains and relationship to city Kitakyushu.

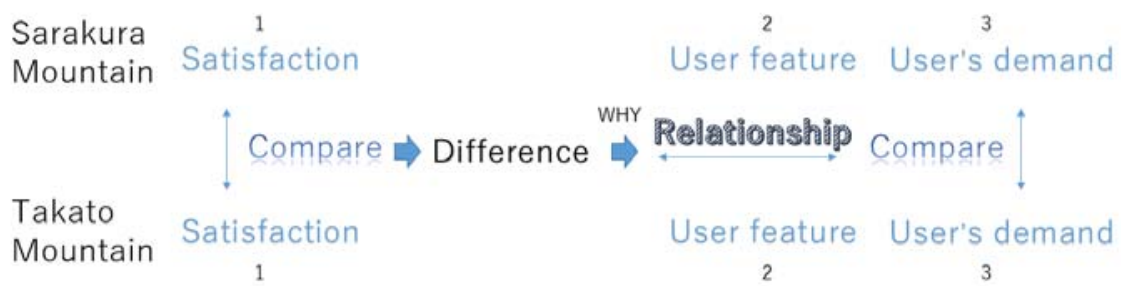

Figure 3: Flow chart of the study. 


\subsection{Study method and period}

Expressive indicators of satisfaction involving core experiences were most salient in explaining variance in general measures of satisfaction. Specific instrumental indicators of satisfaction did not contribute significantly to explaining variance in general measures of satisfaction [1]. We would like to find out how satisfied visitors are with their parks and peak facilities, and the difference in satisfaction between the two similar parks. A questionnaire was designed to collect their satisfaction and other specific information. The two questionnaire uses an approximate problem to show as much as possible how users of the same region differ in terms of how they are used and how satisfied they are. In order to achieve the purpose of the experiment, our investigation includes four aspects.

1. Personal information, including the user's gender, age, occupation, number of visitors, and personnel structure. For example, singles, couples, senior couples, couples with children, or colleagues and friends come to visit. These tags are expected to be classified into different types of users.

2. Tour information, which shows how the users use the facilities and the peak area, including peak arrival time, is expected to down time, the actual tour time and longer than expected or shorter, went to the top of transportation, the number and frequency here, and they came to the top of the mountain the main purpose. These also serve as a basis for judging how users use space in the foreground.

3. Satisfaction data. Indicators of user satisfaction were assessed using Likert scale, which allowed users to assess satisfaction with the trip. The question options are divided into overall satisfaction levels, surveys on the satisfaction of different parts of the observation experience, the environment experience, and the service experience.

4. Personal preferences and suggestions. This part is used to investigate what kind of function the users would like to add to the peak, and what opinions and suggestions are there for the existing prospects. The purpose of this part of the problem is to find out the user's needs for the prospects. So as to support the judgment of different indexes affecting tourist satisfaction.

In order to collect user's data more comprehensively as far as possible, we selected working days and rest days in each of the two parks to collect data on the spot. In order to cover the survey as comprehensive as possible, we observe from 8 a.m. until 8 p.m., this time we are tourists as the main user access, data analysis and conclusion are also only for the main period of observatory tourists use the peak area. In principle, we sent questionnaires to each of the users who received the data so that the views of each visitor could be collected as much as possible during the day. The date of data collection is from May 13, 2017 to May 16th. In the end, 210 valid questionnaires were recovered from Sarakura Mountain, and 156 valid questionnaires were recovered from Takato Mountain.

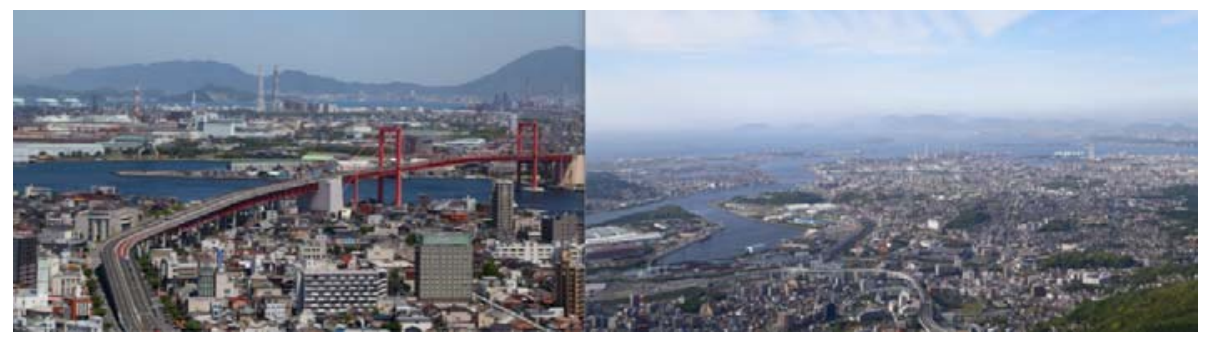

Figure 4: Viewing form Takato observatory (left) and Sarakura (right) observatory. 


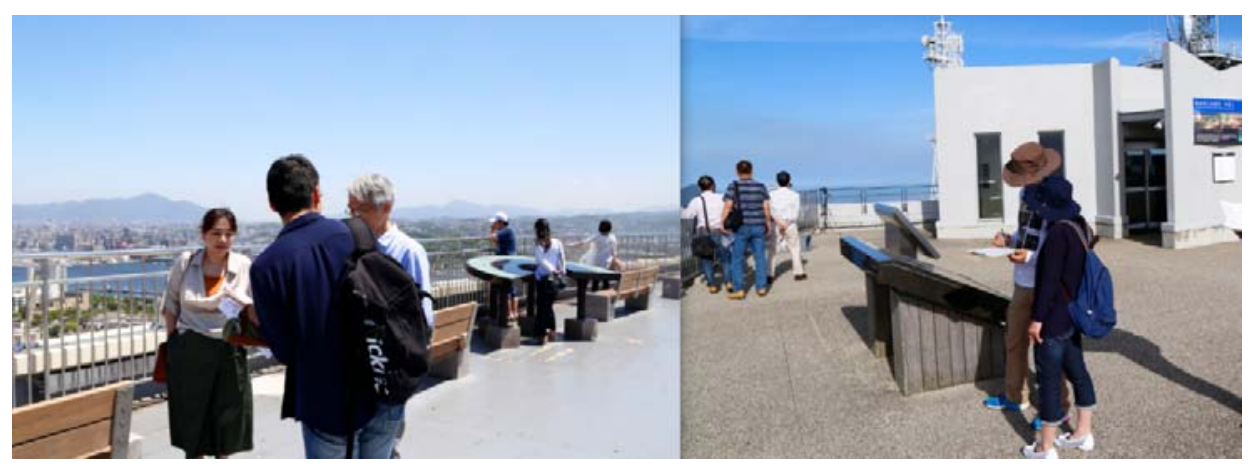

Figure 5: User answering the questionnaire in Takato (left) and Sarakura (right) Mountain.

\section{SURVEY RESULT}

\subsection{Overall satisfaction}

Overall satisfaction was broadly similar across the two subjects, with approximately $61 \%$ of respondents giving the highest assessment of the visiting experience overall. The Sarakura Mountains in the overall level of satisfaction is a little bit higher.

But it is worth noting that the overall level of satisfaction does not mean that the prospects are impeccable in design management. In the sub item statistics, the questionnaire carried out further satisfaction survey on specific aspects. With no accident, the experience of the scenery almost all user gave the highest evaluation. Beautiful scenery and open field of vision of the two peaks take users good feelings. It is probably because the most thing that tourists expected were the view from top of the mountain, so beautiful scenery of the city to enhance the user's psychological feeling. This also shows that the prospect of location selection, vision oriented design, there is a place worthy of recognition. The outlook meets the user's main needs.

The overall high score is gratifying, indicating that tourist satisfaction levels remain at a high level. On this indicator, the gap between mount Sarakura and mount Takato is not large, with 85 points and 82 points, respectively. We think it should be within the reasonable scope, does not represent the Sarakura mountain than Takato mountain has obvious advantages. Then we compared gender differences, and overall satisfaction was better for men than for women. This is similar result reflected to the two mountains. According to the analysis of the follow-up survey, the reason may be because women are more mind mountaintops strong wind and sunshine. The peak area lack of wind and sun shade deck those cause inconvenience. In addition, there are women mentioned cable station and peak viewing platform have distance, the road conditions in general, not suitable for walking with high heels, cause a lower satisfaction degree.

\subsection{Difference in detail}

Of course, we are not satisfied with this. In other projects, we found that the field that observatory was not satisfactory. The convenience of the Takato Mountain is not satisfactory, and the comfort degree of Sarakura Mountain is lower. Contrary to our expectation, the Takato Mountain, due to its lower elevation, is more convenient and should have a greater advantage in terms of convenience. This phenomenon has aroused our interest. In the rest of the environment and the evaluation of the specific facilities, there is no obvious gap between the evaluations of the satisfaction of the two observatories. 


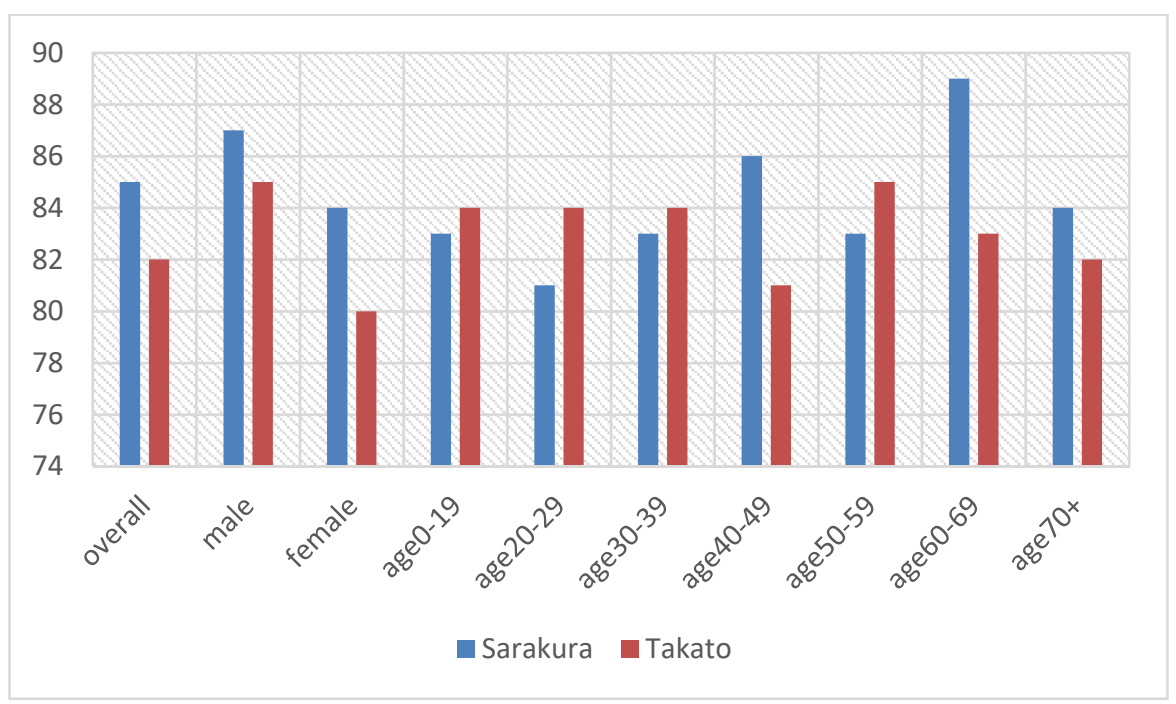

Figure 6: Satisfaction degree towards basic information.

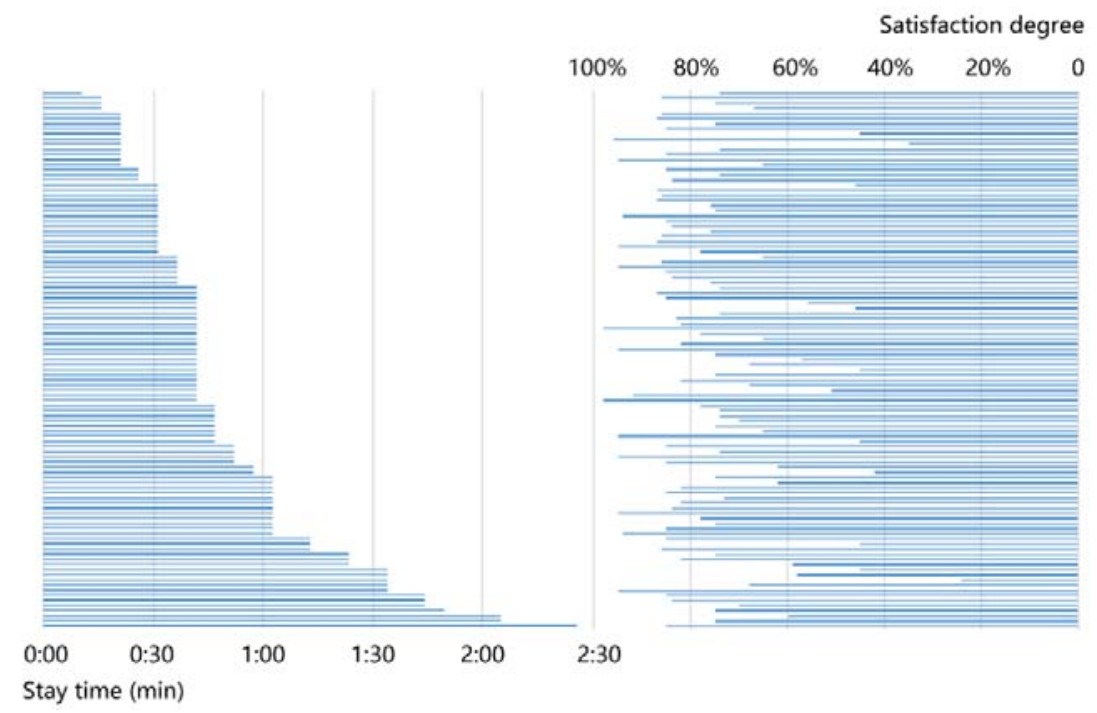

Figure 7: Stay time on the peak area have barely relationship to the satisfaction of visitors.

Thus, around this distinction, we try to compare other factors associated with satisfaction in order to discover the causes that affect this outcome.

We first compare the personal information of the two different mountain visitors, both in terms of occupation and religion, and there is little difference between them.

We also compared the other corresponding indicators. For example, the age of the tourist and the number of people coming together. Among the many visitors, the visitors were classified as single, young couples, middle-aged couples, elderly couples, and parents with 
children. Visitors with children tend to stay longer at the prospect, but in surveys of satisfaction this is consistent with findings from other tourist types.

Next, we collected residence time, hoping to capture the relationship between retention time and satisfaction. According to general opinion, visitors who are more satisfied with peak areas should stay at the peak for longer periods of time. The retention time in our data is calculated according to the arrival time and expected departure time of tourists in the questionnaire. It represents only the tendency of visitors to stay, which may not be consistent with the actual residence time of the tourist. But to our surprise, there was no significant relationship between respondents' satisfaction and length of stay in the survey of all the questionnaires. Visitors who have only a short stay on top of the hill also have high scores, and at the same time, no law of higher satisfaction has been found in surveys of tourists who have stayed a long time.

\subsection{Findings}

Finally, we find that the most important part of the satisfaction is the arrival method of tourists. Takato in this item is divided into walking, driving, and others, which is imaged as a few tourists may come by bicycle and such on. Sarakura also offers an access way to take a cable car. We found that in Sarakura Mountain, walking and cable cars arrived at the top of the mountain, visitors were much more satisfied than tourists driving to the top of the mountain. On the Takato Mountain, the result is the opposite. The tourists who drive here are more satisfied than the tourists who arrive on foot.

\section{ANALYSIS}

In order to explain this phenomenon, we classify them according to different ways of reaching the top of the mountain, and compare the similarities and differences between them. We analyse the phenomenon from the purpose of visitors.

We found that people with different ways of transportation to get here were the most significant indicator to clarify the people came here. The purpose of people coming to the top of the mountain is strongly related to the indicator that the access method they came here.

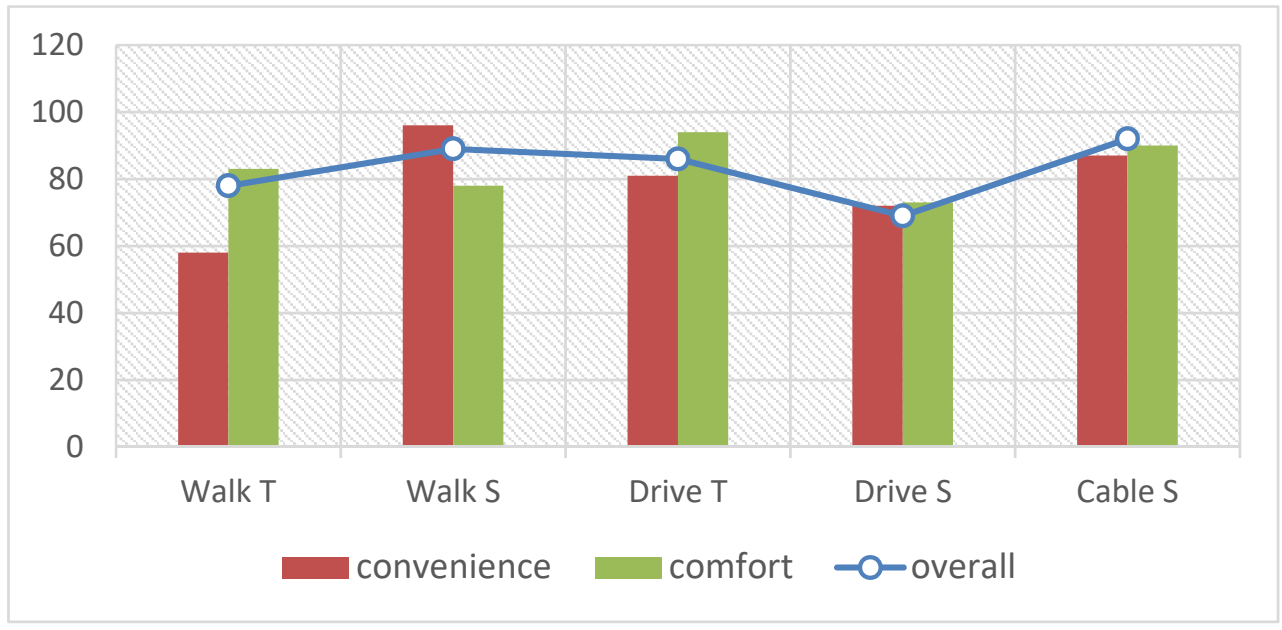

Figure 8: Satisfaction degree by different access method of Takato and Sarakura Mountain. 


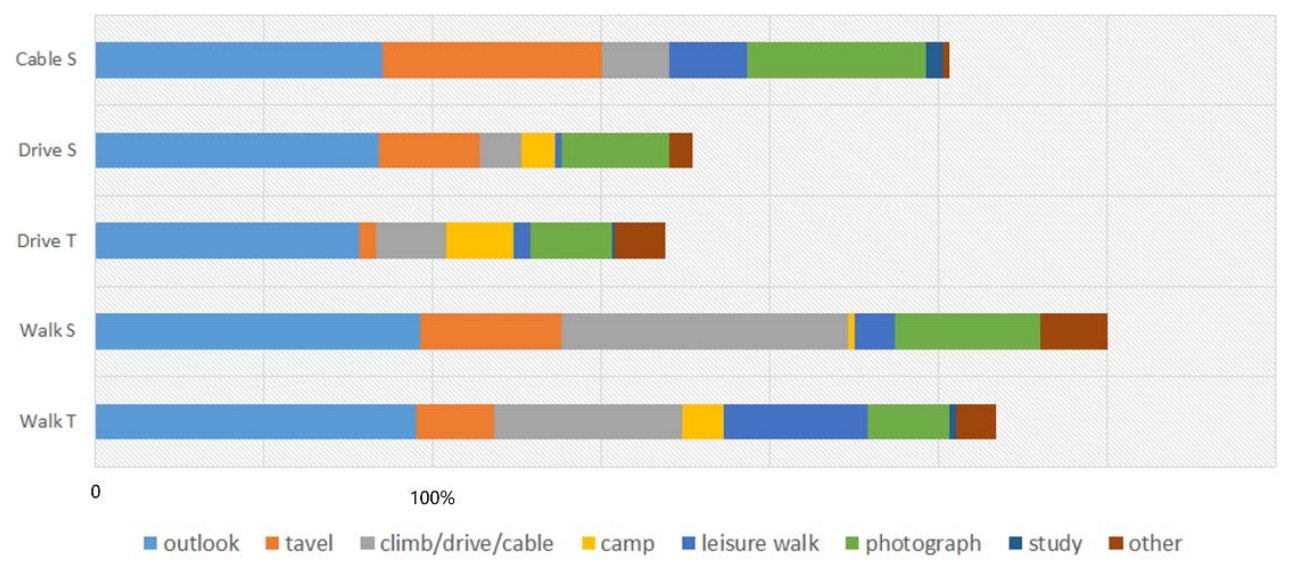

Figure 9: Purpose of users by access method.

There is no doubt that almost all of the interviewees, came here for overlooking the landscape as a main purpose. And because Sarakura Mountain as a higher height, is more well-known mountain in Japan, as a tourist visiting more crowded than Takato Mountain obviously. Photography as one of the purpose in the proportion of the crowd is also higher than the Takato Mountain.

What increased our interest is the item of "climb/drive/cable" in this survey, this option in the questionnaire text representation for tourists to climb the mountain as the purpose, to drive tourists as you go for a ride, for tourists to come to the cable is come to experience the cable car. The respondents had an interesting disagreement about the answer. For this purpose, visitors are not distinguished according to the two mountains, but there is an intersection. On the whole, more tourists climb mountains than motorists. But in the comparison of mountain climbing, Sarakura is obviously higher than Takato, while in driving tourists, Takato is obviously higher than Sarakura. This result is consistent with the degree of satisfaction of different respondents.

Sarakura Mountain as tourist attractions, tourists come to the purpose here is clear. Hiking tourists to the mountain whose satisfaction degree is barely dependent on facilities in peak area. The procession approach to the peak is more critical, with lower needs of convenience, and shows higher satisfaction degree overall. Meanwhile, the tourists who drove to the road, because of the lack of stop on the way, took the peak as the destination directly, the higher height and the long distance were inconvenient, uncomfortable and boring experience. This process affected their experience when they came to the top of the mountain and had higher expectations for the peak facilities and the gazebo.

Takato mountain to the contrary, unlike the Sarakura Mountain which is famous, the height is relatively low, tourist's basic to the nearby public, people tend to plan in addition to overlooking the purpose outside, such as leisure, walking etc. The Takato Mountain therefore has less nature mountain feature, and has more feature of the public park. As a park, pedestrian accessibility is a major reason, explaining the big difference between walking tourists and driving tourists in terms of specific satisfaction. Visitors to mount Takato often do not enjoy the process of climbing the mountain. They look forward to reaching the top of 
the mountain as soon as possible. Therefore, the low mountain needs a more convenient way of arrival.

That is to say, there is a reason for the correlation between arrival and satisfaction. Because the difference in the way people arrive at the destination itself confirms the change in the satisfaction of people arriving in different modes of transportation. The difference in the performance of the two mountains is a case worthy of reference and may be of similar significance to other similar objects and public parks.

\section{SUMMARY}

In the survey of satisfaction degree, both the Takato Mountain and the Sarakura Mountain represented good scores. We can improve the peak facilities for different groups of people according to the difference in people's satisfaction with specific projects. Sarakura Mountain should focus on landscape design and supporting facilities leading to the peak roads and climbing roads. The Takato Mountain should improve the construction of the peak facilities, provide more functions, as a three-dimensional city park, for the public's daily leisure use.

The most important factor to consider in the design and operation of peak facilities is the way tourists arrive. Depending on the nature of each peak terrace, visitors will have different needs for it. Among the factors that reflect tourists' purpose, the way they come is the best way to show different types of tourists. Visitors' satisfaction with the tourist experience also varies largely according to the project.

\section{REFERENCE}

[1] Noe, F.P., Measurement specification and leisure satisfaction. Leisure Sciences, 9(3), pp. 163-172, 1987. 